\title{
Glutathione as an antioxidant marker: determination of glutathione concentration in the breast muscles and liver of broilers supplemented with different selenium sources
}

\author{
Karolína Mikulková1, Josef Illek¹, Zdenka Bezděková ${ }^{2}$ Ivana Šimková ${ }^{2}$ \\ University of Veterinary and Pharmaceutical Sciences Brno, \\ ${ }^{1}$ Faculty of Veterinary Medicine, Large Animal Clinical Laboratory, \\ ${ }^{2}$ Faculty of Veterinary Medicine, Ruminant and Swine Clinic, Brno, Czech Republic
}

Received April 4, 2018

Accepted April 23, 2019

\begin{abstract}
The aim of the study was to determine the influence of different selenium sources on antioxidant properties. The glutathione (GSH) concentration and glutathione peroxidase (GPx) activity were measured in the breast muscles and liver of 60 one-day-old broiler chickens. Another goal was to compare these indices with the weights of individual tissues and the live weight of broilers. The broilers were divided into 4 groups according to the selenium source: group 1 (control), group 2 (selenized yeast), group 3 (selenomethionine), group 4 (sodium selenite). Treatment groups were supplemented with $0.2 \mathrm{mg}$ of additional selenium $/ \mathrm{kg}$. No significant changes in the hepatic GSH concentrations $(P>0.05)$ were found in the experimental groups compared to control. Significantly higher GSH concentration $(P<0.05)$ was found in breast muscles of broilers in group 4 (sodium selenite) compared to control. However, no positive effect of selenium supplementation in the form of sodium selenite was observed. The differences in the GPx activity in breast muscles and liver between the experimental groups and the control group were not significant $(P>0.05)$. No significant differences were recorded in the experimental groups compared to control in relation to the GSH concentration and GPx activity measured in the tissues. A significantly positive correlation was noted between mean GPx activity in breast muscle and breast muscle weight $(P<0.01 ; \mathrm{r}=0.3790)$ and live weight $(P<0.05 ; \mathrm{r}=0.2690)$. Although changes in the GSH concentration and GPx activity were recorded in some experimental groups, the selected dose of additional selenium appeared to be too low to affect these concentrations and the antioxidant defence system.
\end{abstract}

Antioxidant system, glutathione peroxidase, selenium supplementation, broiler chickens, tissue

Glutathione is a tripeptide with a thiol group present at high concentrations in various cells and tissues (Shaik and Mehvar 2006; Cappiello et al. 2013). It is composed of glutamate, cysteine and glycine ( $\gamma$-L-glutamyl-L-cysteinylglycine) and exists in millimolar concentrations (Kaplowitz et al. 1985). Glutathione is present in cells in its reduced form (GSH) and in oxidized forms - glutathione disulphide (GSSG) and glutathione mixed disulphides (Cappiello et al. 2013).

The structure of glutathione, specifically its two forms, is related to its function and role in the organism (Meister 1988). Glutathione protects cells from oxidative stress directly by scavenging reactive oxygen species (ROS) as free radicals and peroxides that are formed in metabolism and by using glutathione-dependent enzymes such as glutathione peroxidase (GPx) and glutathione S-transferase (GST) (Meister 1983; Cappiello et al. 2013). For this reason, it is an extremely important endogenous antioxidant and plays a key role in the antioxidant defence system (Enkvetchakul et al. 1995). The imbalance of the antioxidant defence system in favour of prooxidants initiates oxidative stress and leads to the oxidation of different biological substrates - macromolecules (the reactive - $\mathrm{OH} \cdot$ radical attacks lipids, DNA, proteins). Thus, oxidative stress may be the reason for processes such

Address for correspondence:

Mgr. Karolína Mikulková

Large Animal Clinical Laboratory

Faculty of Veterinary Medicine

University of Veterinary and Pharmaceutical Sciences Brno

Palackého tř. 1946/1, 612 42, Brno, Czech Republic 
as lipid peroxidation, protein oxidation, membrane damage, carcinogenesis and other cell damage (Kaplowitz et al. 1985; Miller et al. 1993).

The main function of glutathione is reduction of hydrogen peroxide $\left(\mathrm{H}_{2} \mathrm{O}_{2}\right)$ and organic peroxides (lipid peroxides); these reactions are catalysed by GPx and GST (Meister 1983; Kaplowitz et al. 1985). The thiol group, present in reduced glutathione (GSH), acts as a free radical scavenger. During the reduction of $\mathrm{H}_{2} \mathrm{O}_{2}$ and lipid peroxides to $\mathrm{H}_{2} \mathrm{O}$ and alcohols, GSH is oxidized to GSSG and serves as an electron donor. Oxidized glutathione is converted back to GSH by glutathione reductase using reduced nicotinamide adenine dinucleotide phosphate (NADPH) (Cao et al. 2013). In healthy cells and tissues, the presence of the reduced form $(\mathrm{GSH})$ predominates. Under pathophysiological conditions the GSH:GSSG ratio decreases. Oxidative stress that is caused by an imbalance between prooxidants and antioxidants can be the reason for an increase to the glutathione disulphide concentration. Thiol-disulphide exchange reactions are another type of conversion of intracellular GSH to GSSG catalysed by transhydrogenase (EC 1.8.4.2 - protein-disulphide reductase [glutathione]). These reactions are part of many metabolic and physiological functions such as protein synthesis and degradation and the activation and inactivation of enzymes (Meister 1983; Meister and Anderson 1983). According to several studies, the GSH/GSSG ratio may be considered the best indicator of oxidative stress (Tarin 1966; Tarin et al. 1998; Avanzo et al. 2001; Kaneko et al. 2001).

Selenium is considered an essential trace element because of its irreplaceable role in the organism. It regulates the functions of the antioxidant defence system through the GSH and Se-containing antioxidant enzyme GPx (Mahmoud and Edens 2003; Horký 2014). The aim of this study was to evaluate the effect of additional selenium in the diet on the GSH concentration and GPx activity in the breast muscles and liver of broiler chickens. The breast muscle, liver and live weights of broilers were recorded and the correlation between weights and antioxidant properties were evaluated.

\section{Materials and Methods}

Animals and diets

The study was carried out using a total of 60 one-day-old broiler chickens, following local Research Ethics Committee approval (84722/2014-MZE-17214). The chickens were divided into 4 groups -1 control group and 3 treatment groups. Each group contained 15 chickens. All experimental groups were fed a basal diet (Table 1) and the 3 treatment groups were also supplemented with $0.2 \mathrm{mg}$ of selenium $/ \mathrm{kg}$ in three different form of additional selenium. The experimental groups were as follows: group 1 (control), group 2 (selenized yeast) supplemented with $118.9 \mathrm{~g} / \mathrm{t}$ feed, group 3 (selenomethionine) supplemented with $8.70 \mathrm{~g} / \mathrm{t}$ feed and group 4 (sodium selenite) supplemented with $6.67 \mathrm{~g} / \mathrm{t}$ feed. The chickens were fed a Starter BR1 until 2 weeks of age, followed by a Grower BR2 until 5 weeks of age and a Finisher BR3 from 5 weeks of age (MTD Ústrašice, Czech Republic). Water and feed were provided ad libitum. After 6 weeks of feeding the chickens were stunned by electricity and slaughtered by cervical dislocation. Their body weight was recorded. Liver and breast muscle samples were immediately taken, weighed and stored at $-70^{\circ} \mathrm{C}$.

\section{Sampling and analysis}

Homogenization of samples

The tissues were washed in $0.9 \% \mathrm{NaCl}$ solution and then homogenized. Disperser T10 basic ULTRA-TURRAX (IKA, Staufen, Germany) was used for homogenization. Tissues for GSH determination were homogenized in precipitation reagent at a ratio of 1:20 (supplied in the kit) and tissues for GPx determination in 50 mM sodium phosphate buffer ( $\mathrm{pH} 7.4$ ), where $1 \mathrm{ml}$ of solution per $0.12 \mathrm{~g}$ of tissue was used. The samples were kept on ice during homogenization. After centrifugation at $3000 \mathrm{~g}$ for $10 \mathrm{~min}$ at $4{ }^{\circ} \mathrm{C}$, the supernatant was collected and used for the assay. The tissues were stored at $-70^{\circ} \mathrm{C}$ and the $\mathrm{GSH}$ concentration and GPx activity were determined immediately after homogenization.

Total glutathione determination

Total glutathione concentrations were measured with a BIOXYTECH GSH-420 kit (OxisResearch, Portland, Oregon, USA) using the quantitative colorimetric method. This method is based on the formation of chromophoric thione and the chemical reaction proceeds in three steps. First, oxidized glutathione (GSSG) is reduced to the reduced form $(\mathrm{GSH})$ by adding the reducing agent tris(2-carboxyethyl)phosphine (TCEP). The 
Table 1. Basal diet composition.

\begin{tabular}{|c|c|c|c|}
\hline Components (\%) & Starter BR1 & Grower BR2 & Finisher BR3 \\
\hline Wheat & 40.000 & 51.880 & 56.450 \\
\hline Maize & 19.450 & 10.000 & 10.000 \\
\hline Soybean meal & 32.800 & 29.500 & 24.600 \\
\hline Soybean oil & 4.000 & 5.000 & 5.800 \\
\hline L-lysine $\mathrm{HCl}$ & 0.170 & 0.220 & 0.200 \\
\hline DL-methionine & 0.060 & 0.100 & 0.120 \\
\hline L-threonine & 0.060 & 0.080 & 0.060 \\
\hline Limestone & 1.500 & 1.500 & 1.400 \\
\hline Salt & 0.260 & 0.250 & 0.240 \\
\hline MCP & 1.000 & 0.770 & 0.500 \\
\hline $\mathrm{Na}_{2} \mathrm{CO}_{3}$ & 0.200 & 0.200 & 0.130 \\
\hline Premix AMV BR1 Plus & 0.500 & - & - \\
\hline Premix AMV BR2 Plus & - & 0.500 & - \\
\hline Premix AMV BR3 Plus & - & - & 0.500 \\
\hline \multicolumn{4}{|l|}{ Nutrient content } \\
\hline Crude protein $(\mathrm{g} / \mathrm{kg})$ & 214.700 & 204.740 & 187.550 \\
\hline $\mathrm{ME}(\mathrm{MJ} / \mathrm{kg})$ & 12.333 & 12.635 & 13.011 \\
\hline Lysine (g/kg) & 12.970 & 12.520 & 11.030 \\
\hline Methionine (g/kg) & 5.980 & 5.820 & 5.490 \\
\hline Met+Cys (g/kg) & 9.730 & 9.460 & 8.880 \\
\hline $\mathrm{Ca}(\mathrm{g} / \mathrm{kg})$ & 9.060 & 8.628 & 7.656 \\
\hline$P(g / k g)$ & 6.535 & 5.988 & 5.230 \\
\hline $\mathrm{Na}(\mathrm{g} / \mathrm{kg})$ & 1.779 & 1.761 & 1.523 \\
\hline
\end{tabular}

chromogen (4-chloro-1-methyl-7-trifluoromethylquinolinium methylsulphate) is added to form thioethers. At a pH highter than 13 (caused by adding the buffer) GSH thioether is transformed into the chromophoric thione by $\beta$-elimination. The absorbance of the resultant product is measured at $420 \mathrm{~nm}$ and is directly proportional to the GSH concentration. An Evolution 160 spectrophotometer (Thermo Scientific, Waltham, Massachusetts, USA) was used to measure GSH concentrations. The results were expressed in $\mu \mathrm{mol} / 1$ and converted to $\mu \mathrm{mol} / \mathrm{g}$ of tissue. The preparation of samples for determination and the assay method were performed as described in the manual.

Glutathione peroxidase activity

The GPx activity was measured by the RANSEL kit (Randox Laboratories Ltd., Crumlin, UK) using a UV method based on that of Paglia and Valentine (1967). This method is based on measuring the decrease in absorbance at $340 \mathrm{~nm}$ due to NADPH oxidation. Glutathione (GSH) is oxidized by cumene hydroperoxide into its oxidized form (GSSG). The reaction is catalysed by GPx. Immediately, GSSG is converted to GSH and NADPH is oxidized to $\mathrm{NADP}^{+}$. The reaction is catalysed by glutathione reductase. The automatic biochemical analyser Liasys (AMS, Guidonia, Italy) was used to measure the GPx activity. The results were expressed in $\mu \mathrm{kat} / 1$ and converted to $\mu \mathrm{kat} / \mathrm{g}$ of tissue. The assay method was performed as described in the manual.

\section{Statistical analysis}

The results obtained were tested for the homogeneity of variances (Hartley-Cochran-Bartlett test) and the normality of distribution (Shapiro-Wilk test). The data were analysed statistically by one-way analysis of variance (ANOVA) followed by Fisher LSD post hoc test. All results were expressed as the mean value (x) \pm standard error (SE). The relationship between the measured antioxidant properties in tissues and tissue weight and live weight were evaluated by the correlation coefficient and the significance of correlation using linear regression analysis.

\section{Results}

The results of the antioxidant properties are presented in Table 2. The lowest mean GSH concentration in liver was recorded in the control group $(1.99 \mu \mathrm{mol} / \mathrm{g})$ compared 
Table 2. Antioxidant properties in tissues of broiler chickens of the study groups (results are expressed as mean \pm standard error).

\begin{tabular}{lcccc}
\hline Group & \multicolumn{2}{c}{ GSH $(\mu \mathrm{mol} / \mathrm{g})$} & \multicolumn{2}{c}{ GPx $(\mu \mathrm{kat} / \mathrm{g}$ tissue $)$} \\
\hline 1 & Breast muscles & Liver & Breast muscles & Liver \\
Control & $1.18 \pm 0.13^{\alpha}$ & $1.99 \pm 0.14$ & $2.08 \pm 0.16$ & $31.69 \pm 1.15$ \\
2 & & & & \\
Selenized yeast & $0.95 \pm 0.12$ & $2.17 \pm 0.14$ & $1.89 \pm 0.12$ & $29.03 \pm 1.00^{\mathrm{A}}$ \\
3 & & & $2.27 \pm 0.18$ & $31.63 \pm 1.53$ \\
Selenomethionine & $1.08 \pm 0.11$ & $2.04 \pm 0.10$ & & $34.97 \pm 1.56^{\mathrm{B}}$ \\
\hline
\end{tabular}

Significant differences between groups are indicated by using different superscripts in columns: $\alpha, \beta-P<0.05$, A, B $-P<0.01$; GSH - glutathione; GPx - glutathione peroxidase.

to the other experimental groups. The differences in the increases were not, however, significant $(P>0.05)$. The mean value of the GSH concentration in breast muscles did not show any significant changes $(P>0.05)$ in the experimental groups caused by selenium supplementation compared to the control group. No significant differences $(P>0.05)$ between the control and experimental groups were found in relation to the mean GPx activity in breast muscles and liver.

The tissue weights and live weights of broiler chickens are presented in Table 3 . The correlations between the measured antioxidant properties in tissues (breast muscles, liver) and tissue weight and live weight were evaluated (Tables 4, 5). A significantly positive correlation was found between mean GPx activity in breast muscles and breast muscles weight $(P<0.01 ; \mathrm{r}=0.3790)$ and live weight $(P<0.05 ; \mathrm{r}=0.2690)$. These two correlations are shown in Plate I, Figs 1 and 2. No significantly positive correlation was determined between mean breast muscle GSH concentration and breast muscle weight $(P>0.05 ; \mathrm{r}=$ $0.1687)$ and live weight $(P>0.05 ; \mathrm{r}=0.1047)$ and between mean liver GSH concentration and liver weight $(P>0.05 ; \mathrm{r}=0.0599)$. Negative correlations were recorded between mean liver GSH concentration and live weight $(P>0.05 ; \mathrm{r}=-0.0526)$ and between mean liver GPx activity and liver weight $(P>0.05 ; \mathrm{r}=-0.0848)$ and live weight $(P>0.05 ; \mathrm{r}=$ $-0.0604)$.

Table 3. Tissue weight and live weight of broiler chickens of the study groups (results are expressed as mean \pm standard error).

\begin{tabular}{lccc}
\hline Group & $\begin{array}{c}\text { Breast muscle weight } \\
(\mathrm{g})\end{array}$ & $\begin{array}{c}\text { Liver weight } \\
(\mathrm{g})\end{array}$ & $\begin{array}{c}\text { Live weight } \\
(\mathrm{g})\end{array}$ \\
\hline 1 & $633 \pm 29.10$ & $55 \pm 2.63$ & $2808 \pm 103.77$ \\
Control & $594 \pm 28.5$ & $52 \pm 2.27$ & $2717 \pm 107.83$ \\
2 & & & \\
Selenized yeast & $674 \pm 25.18$ & $58 \pm 3.55$ & $3053 \pm 97.89$ \\
3 & & & \\
Selenomethionine & $635 \pm 17.80$ & $60 \pm 2.56$ & $2989 \pm 58.70$ \\
\hline
\end{tabular}

Non-significant differences between groups were recorded $(P>0.05)$. 
Table 4. Correlation coefficients (r) between measured antioxidant properties in breast muscles and breast muscle weight and live weight.

\begin{tabular}{lcccc}
\hline & GSH breast muscles & GPx breast muscles & Breast muscle weight & Live weight \\
\hline GSH breast muscles & & & 0.1687 & 0.1047 \\
GPx breast muscles & & & $0.3790^{\mathrm{A}}$ & $0.2690^{\alpha}$ \\
Breast muscle weight & 0.1687 & $0.3790^{\mathrm{A}}$ & & \\
Live weight & 0.1047 & $0.2690^{\alpha}$ & & \\
\hline
\end{tabular}

Significance of correlations: $\alpha-P<0.05$, A - $P<0.01$; GSH - glutathione; GPx - glutathione peroxidase.

Table 5. Correlation coefficients (r) between measured antioxidant properties in liver and liver weight and live weight.

\begin{tabular}{lcccc}
\hline & GSH liver & GPx liver & Liver weight & Live weight \\
\hline GSH liver & & & 0.0599 & -0.0526 \\
GPx liver & & & -0.0848 & -0.0604 \\
Liver weight & 0.0599 & -0.0848 & & \\
Live weight & -0.0526 & -0.0604 & & \\
\hline
\end{tabular}

Non-significant differences between the groups were recorded: $P>0.05$;

GSH - glutathione; GPx - glutathione peroxidase.

\section{Discussion}

The inorganic form of selenium-selenite, selenate - has been used as the main selenium source for poultry feeds. Naturally, the source of selenium for animals is organic selenium in the forms of selenocysteine, selenomethionine (Surai 2002). Organic forms of selenium are present in selenized yeast and there is increasing interest in this type of selenium source (Surai and Dvorska 2002). Selenomethionine is easily absorbed and can be stored as a reserve in case of need. It is present in skeletal muscles, erythrocytes, the pancreas, liver, kidney and stomach and the gastrointestinal mucosa (Schrauzer 2000; Surai 2002).

The GSH concentration in liver is about 25 to $50 \%$ lower in broilers compared to mammals (Beers et al. 1992; Enkvetchakul et al. 1993). The range of GSH concentrations in the liver reported by several studies is $2.0-4.5 \mu \mathrm{mol} / \mathrm{g}$, as summarized by Enkvetchakul et al. (1995). In our study, the hepatic GSH concentration was around $2.0 \mu \mathrm{mol} / \mathrm{g}$ in all groups $(1.99-2.17 \mu \mathrm{mol} / \mathrm{g})$ which corresponds with previous studies. Hepatic GSH concentrations were increased in all experimental groups compared to the control group, however, the differences were not significant $(P>0.05)$. Changes in the GSH concentration may have been caused by selenium supplementation and its positive effect on the antioxidant system, but due to their non-significance, this assumption cannot be confirmed. In contrast to GSH concentrations in the liver, the highest mean GSH concentration in breast muscle $(1.18 \mu \mathrm{mol} / \mathrm{g})$ was found in the control group. No influence of selenium supplementation on GSH concentrations in breast muscle was found. This may be caused by insufficient absorption of selenium in breast muscle which is inconsistent with several studies concerning the storage of the organic and inorganic forms of selenium in breast muscle (Kuricová et al. 2003; Choct et al. 2004; Payne and Southern 2005). Dlouhá et al. (2008) and Skrrivan et al. (2008) reported that the addition of sources of organic selenium leads to increased selenium concentration in chicken breast muscle. On the basis of these findings, we predicted an increase in the GSH concentration in breast muscle in experimental groups compared to the control group.

Many authors have described the influence of selenium supplementation on increasing 
GPx activity. Arai et al. (1994) reported that the addition of selenium in organic form increases GPx activity in chicken liver. According to the studies by Shiobara et al. (1998), selenium supplementation in rats significantly increases GPx activity and reduces peroxidation of lipids. According to Pappas et al. (2005), selenium supplementation can participate in increasing GPx activities in the blood, liver and breast muscle. Studies by Piršljin et al. (2008) showed that organic selenium supplementation has a positive effect on the antioxidant system due to higher activity of GPx in chickens during the experiment. The present study showed significantly increased hepatic GPx activity $(P<0.01)$ in group 4 (sodium selenite) compared to group 2 (selenized yeast), but no significant differences in liver as in breast muscle GPx activity between experimental and control groups were found $(P>0.05)$. However, a higher GPx activity in liver compared to the control group was found in experimental group 4 (sodium selenite) and in the case of breast muscle, GPx activity was increased compared to the control group in experimental groups 3 and 4 supplemented with selenomethionine and sodium selenite.

Non-significant changes in the GSH concentration and GPx activity in experimental groups may be due to an insufficient concentration of additional selenium in the diet. Mahmoud and Edens (2003) and Piršljin et al. (2008) published findings in which the concentrations of additional selenium in experimental groups were 0.46 and $0.3 \mathrm{mg}$ of selenium $/ \mathrm{kg}$. On the other hand, Heindl et al. (2010) reported significantly different breast and thigh meat GPx activity in experimental groups supplemented with 0.15 and $0.30 \mathrm{mg}$ of additional selenium $/ \mathrm{kg}$ compared to the control group.

Enkvetchakul and Bottje (1995) confirmed that a higher GSH concentration correlates with the body weight and age of broilers. This is in agreement with the published findings of Enkvetchakul et al. (1995) in which heavier poultry were found to have higher GSH concentrations. The data from this study also show a positive correlation between GSH concentration and weight except for the correlation between hepatic GSH concentration and live weight where a negative effect was found. However, the correlation between GSH concentration and weight is not significant. Some significant changes were found in the case of correlation between GPx activity and weight.

In conclusion, the selenium sources added to the diet may have a positive effect on the antioxidant properties. However, to achieve significant changes in the GSH concentration and GPx activity, the dose of additional selenium in the diet should be higher. The present study also showed that heavier broilers have an increased GPx activity in breast muscles.

\section{Acknowledgement}

The authors sincerely acknowledge the institutional support.

\section{References}

Arai T, Sugawara M, Sako N, Motoyoshi S, Shimura T, Tsutsui N, Konno T 1994: Glutathione peroxidase activity in tissues of chicken supplemented with dietary selenium. Comp Biochem Physiol 107A: 245-248

Avanzo JL, Mendonca CX, Pugine SM, Cesar MC 2001: Effect of vitamin E and selenium on resistance to oxidative stress in chicken superficial pectoralis muscle. Comp Biochem Physiol, Part C 129: 163-173

Beers KW, Nejad H, Bottje WG 1992: Aflatoxin and glutathione in domestic fowl (Gallus domesticus) I. Glutathione elevation and attenuation by high dietary methionine. Comp Biochem Physiol 101C: 239-244

Cao L, Waldon D, Teffera Y, Roberts J, Wells M, Langley M, Zhao Z 2013: Ratios of biliary glutathione disulfide (GSSG) to glutathione (GSH): a potential index to screen drug-induced hepatic oxidative stress in rats and mice. Anal Bioanal Chem 405: 2635-2642

Cappiello M, Peroni E, Lepore A, Moschini R, Del Corso A, Balestri F, Mura U 2013: Rapid colorimetric determination of reduces and oxidized glutathione using an end point coupled enzymatic assay. Anal Bioanal Chem 405: 1779-1785

Dlouhá G, Ševčíková S, Dokoupilová A, Zita L, Heindl J, Skřivan M 2008: Effect of dietary selenium sources on growth performance, breast muscle selenium, glutathione peroxidase and oxidative stability in broilers. Czech J Anim Sci 53: 265-269 
Enkvetchakul B, Anthony NB, Bottje WG 1995: Liver and blood glutathione in male broiler chickens, turkeys, and quail. Poultry Sci 74: 885-889

Enkvetchakul B, Bottje WG 1995: Influence of diethyl maleate and cysteine on tissue glutathione and growth in broiler chickens. Poultry Sci 74: 864-873

Enkvetchakul B, Bottje WG, Anthony N, Moore R, Huff W 1993: Compromised antioxidant status associated with ascites in broilers. Poultry Sci 72: 2272-2280

Heindl J, Ledvinka Z, Englmaierová M, Zita L, Tůmová E 2010: The effect of dietary selenium sources and levels on performance, selenium contect in muscle and glutathione peroxidase activity in broiler chickens. Czech J Anim Sci 55: 572-578

Horký P 2014: Influence of increased dietary selenium on glutathione peroxidase activity and glutathione concentration in erythrocytes of lactating sows. Ann Anim Sci 14: 869-882

Choct M, Naylor AJ, Reinke N 2004: Selenium supplementation affects broiler growth performance, meat yield and feather coverage. British Poultry Sci 45: 677-683

Kaplowitz N, Aw TY, Ookhtens M 1985: The regulation of hepatic glutathione. Ann Rev Pharmacol Toxicol 25: 715-744

Kaneko T, Luchi Y, Kawachiya S, Fujii T, Saito H, Kurachi H, Fujii J 2001: Alteration of glutathione reductase expression in the female reproductive organs during the estrous cycle. Biol Reprod 65: 1410-1416

Kuricová S, Boldižárová K, Grešáková L, Bobček L, Levkut M, Leng L 2003: Chicken selenium status when fed a diet supplemented with Se-yeast. Acta Vet Brno 72: 339-346

Mahmoud KZ, Edens FW 2003: Influence of selenium sources on age-related and mild heat stress-related changes of blood and liver glutathione redox cycle in broiler chickens (Gallus domesticus). Comp Biochem Physiol Part B 136: 921-934

Meister A 1988: Minireview: Glutathione metabolism and its selective modification. J Biol Chem 263: 17205-17208

Meister A 1983: Selective modification of glutathione metabolism. Science 220: 472-477

Meister A, Anderson ME 1983: Glutathione. Ann Rev Biochem 52: 711-760

Miller JK, Brzezinska-Slebodzinska E, Madsen FC 1993: Oxidative stress, antioxidants, and animal function. J Diary Sci 76: 2812-2823

Paglia DE, Valentine WN 1967: Studies on the quantitative and qualitative characterization of erythrocyte glutathione peroxidase. J Lab Clin Med 70: 158-169

Pappas AC, Karadas F, Surai PF, Speake BF 2005: The selenium intake of the female chicken influences the selenium status of her progeny. Comp Biochem Physiol 142B: 465-474

Payne RL, Southern LL 2005: Comparison of inorganic and organic selenium sources for broilers. Poultry Sci 84: 898-902

Piršljin J, Milinkovic-Tur S, Ljubic BB, Zdelar-Tuk M 2008: The effect of selenium supplementation on the antioxidative characteristics and lipid peroxidation of chicken blood during fattening and after fasting. Vet archiv 78: 187-196

Shaik IH, Mehvar R 2006: Rapid determination of reduced and oxidized glutathione levels using a new thiol-masking reagent and the enzymatic recycling method: application to the rat liver and bile samples. Anal Bioanal Chem 385: 105-113

Shiobara Y, Youshida T, Suzuki KT 1998: Effects of dietary selenium species on Se concentrations in hair, blood, and urine. Tox Appl Pharm 152: 309-314

Schrauzer GN 2000: Selenomethionine: a review of its nutritional significance, metabolism and toxicity. J Nutr 130: $1653-1656$

Skřivan M, Dlouhá G, Mašata O, Ševčíková S 2008: Effect of dietary selenium on lipid oxidation, selenium and vitamin $\mathrm{E}$ content in the meat of broiler chickens. Czech J Anim Sci 53: 306-311

Surai PF 2002: Selenium in poultry nutrition. 1. Antioxidant properties, deficiency and toxicity. World Poultry Sci J 58: 333-347

Surai PF, Dvorska JE 2002: Effect of selenium and vitamin E content of the diet on lipid peroxidation in breast muscle tissue of broiler breeder hens during storage. Proceedings of Australian Poultry Science Symposium 14: $187-92$

Tarin JJ 1996: Potential effects of age-associated oxidative stress on mammalian oocytes/embryos. Mol Hum Reprod 2: 717-726

Tarin JJ, Ten J, Vendrell FG, Cano A 1998: Dithiothreitol prevents age-associated decrease in oocyte/conceptus viability in vitro. Mol Hum Reprod 13: 381-386 
Plate I

Mikulková K. et al.: Glutathione as an antioxidant ... pp. 157-163

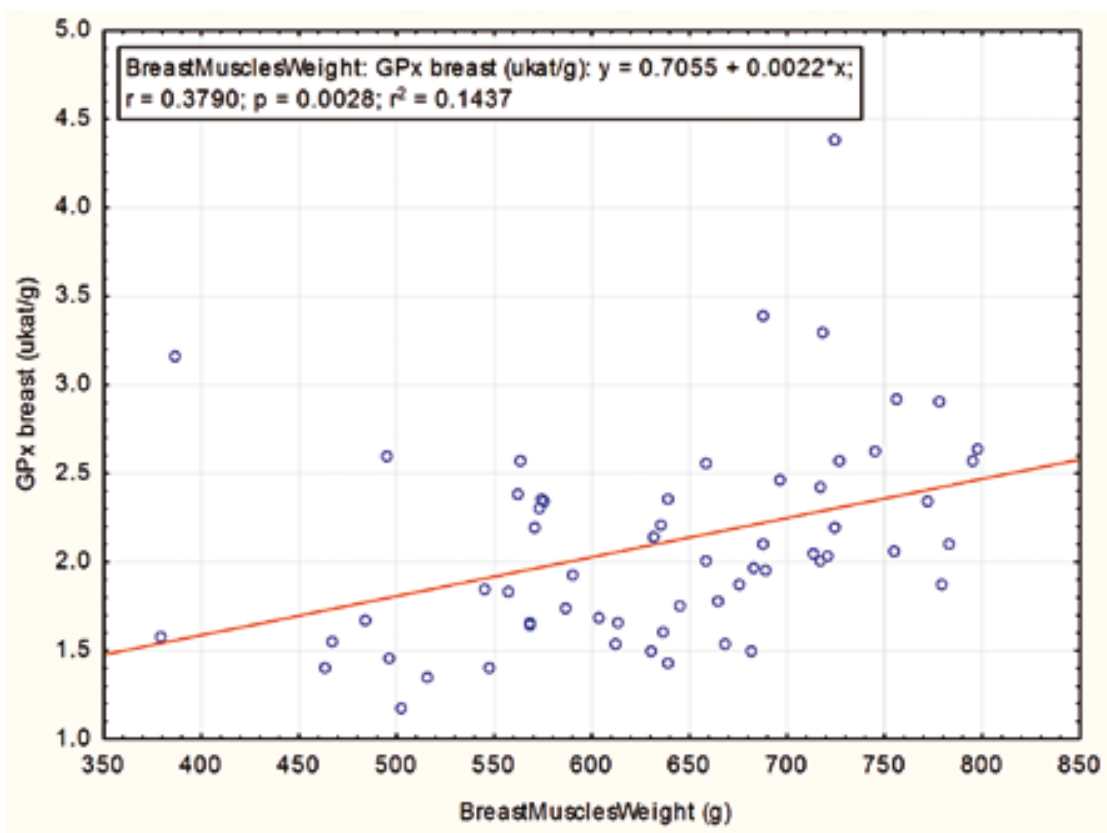

Fig. 1. Correlation between the mean GPx activity in breast muscles and breast muscle weight in broiler chickens

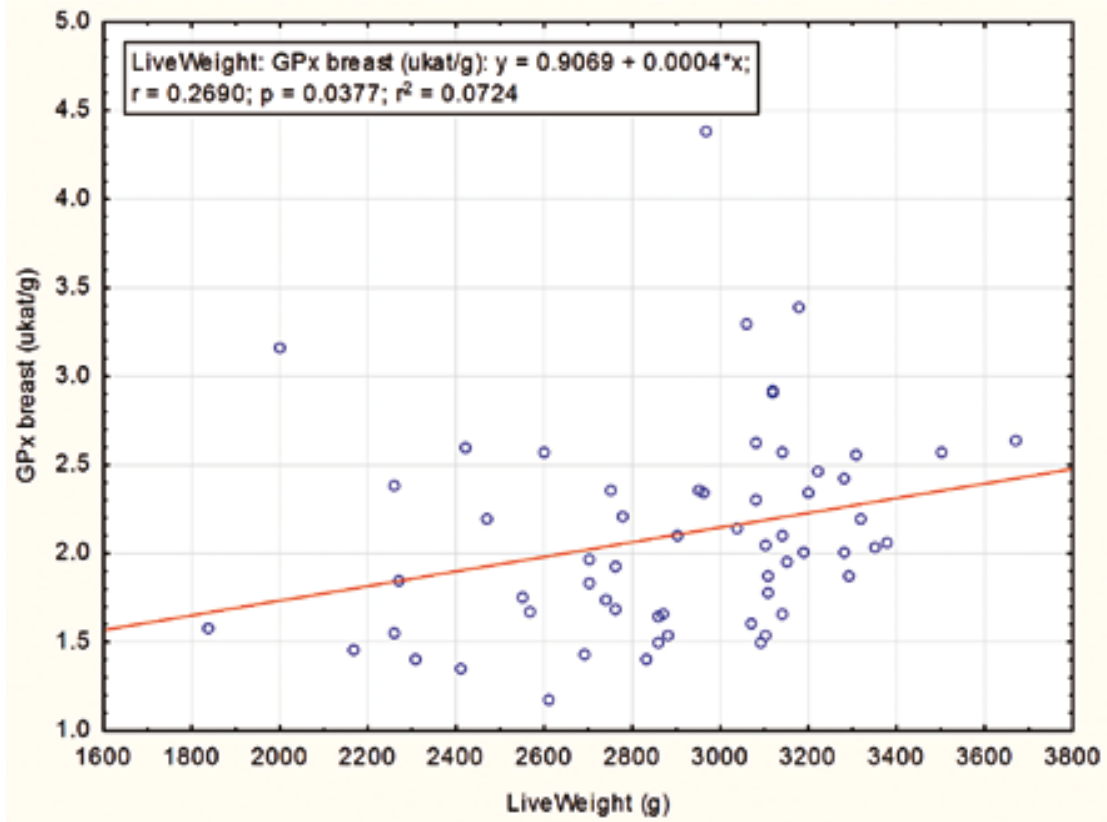

Fig. 2. Correlation between the mean GPx activity in breast muscles and live weight in broiler chickens 